\title{
Caracterização de um isolado de Bidens mosaic virus proveniente de alface.
}

\author{
Gerson Shinia Suzuki, Renan Augusto Cardoso Rosa, Márcio Martinello Sanches, Denise Nakada Nozaki, Marcelo \\ Agenor Pavan, Renate Krause-Sakate.
}

Departamento de Produção Vegetal - Setor Defesa Fitossanitária, Faculdade de Ciências Agronômicas - UNESP, CEP 18603-970, Botucatu-SP, e-mail: renatekrause@fca.unesp.br

Autor para correspondência: Marcio Martinello Sanches (e-mail:marcio@fca.unesp.br)

Data de chegada: 04/01/2008. Aceito para publicação em: 10/03/2009

\section{RESUMO}

Suzuki, G. S.; Rosa, R.A.C.; Sanches, M.M.; Nozaki, D.N.; Pavan, M.A.; Krause-Sakate, R. Caracterização de um isolado de Bidens mosaic virus proveniente de alface. Summa Phytopathologica, v.35, n.3, p.231-233, 2009

Em 2004, plantas de alface com sintomas de mosaico coletadas em São Manuel - SP foram analisadas por microscopia eletrônica, constatando-se presença de partículas típicas de potyvirus com 730 $\mathrm{nm}$ de comprimento. Após purificação biológica por monolesionais em Chenopodium quinoa, o extrato vegetal foi inoculado em uma série de plantas diferenciadoras, verificando-se que o isolado testado foi capaz de infectar C. quinoa e C. amaranticolor induzindo lesões locais seguidas de mosaico sistêmico. Ervilha (Pisum sativum) mostrou-se assintomática, e em diferentes cultivares de alface como Trocadero, White Boston, Regina, Verônica, Lucy Brown, Rafaela,
Tainá, Vera e Laurel foi observado o mosaico. A cultivar Gizele foi tolerante ao vírus. O sequenciamento da região codificadora da proteína capsidial revelou maior identidade de aminoácidos (97\%) deste isolado com o Bidens mosaic virus - BiMV $\left(\mathrm{n}^{\circ}\right.$ de acesso AY960151). Diferentemente dos isolados de BiMV já descritos, este proveniente de alface não foi capaz de infectar Bidens pilosa, Helianthus annuus, Nicotiana tabacum TNN e N. glutinosa. A ocorrência natural do BiMV em alface, causando sintomas semelhantes aos do LMV e a suscetibilidade de várias das cultivares hoje plantadas, servem como um alerta para a correta diagnose do vírus a campo.

Palavras-chave adicionais: BiMV, potyvirus, PVY

\section{ABSTRACT}

Suzuki, G. S.; Rosa, R.A.C.; Sanches, M.M.; Nozaki, D.N.; Pavan, M.A.; Krause-Sakate, R. Characterization of an isolate of Bidens mosaic virus (BiMV) from lettuce. Summa Phytopathologica, v.35, n.3, p.231-233, 2009

In 2004 lettuce plants showing mosaic symptoms collected in São Manuel, SP were analyzed by electron microscopy, and particles with $730 \mathrm{~nm}$ typically from potyvirus were observed. After biological purification by monolesionals on Chenopodium quinoa, this isolate was sap inoculated on a host range assay. The virus infected $C$. quinoa and C. amaranticolor, causing local lesions and systemic mosaic. The virus did not induce symptoms on pea (Pisum sativum), but induced mosaic on the leaves of some lettuce cultivars such as Trocadero, White Boston, Regina, Verônica, Lucy Brown, Rafaela, Tainá, Vera and Laurel. The lettuce cultivar Gizele was tolerant to the virus. The coat protein gene was sequenced, and $97 \%$ aminoacids identity was observed with Bidens mosaic virus - BiMV (GenBank accession number AY960151). Differently of others previously BiMV isolates described, this isolate from lettuce was not able to infect Bidens pilosa, Helianthus annuus, Nicotiana tabacum TNN and N. glutinosa. The natural occurrence of BiMV infecting lettuce and causing mosaic symptoms similar to LMV, also the susceptibility of many lettuce cultivars to BiMV, could be an alert to the correct diagnosis of the viruses infecting this plant .

Keywords: BiMV, potyvirus, PVY

A cultura da alface (Lactuca sativa) é atacada por inúmeras doenças, dentre as quais no Brasil podemos citar três de etiologia viral como sendo as mais importantes: o mosaico da alface causado pelo Lettuce mosaic virus - LMV, encontrado mundialmente; a doença conhecida como vira-cabeça causada por diferentes espécies do gênero Tospovirus e o engrossamento das nervuras ou "big-vein" causado pelo Mirafiore lettuce big-vein virus - MLBVV e o Lettuce big-vein associated virus - LBVaV (10).

Dentre os vírus de menor importância encontra-se a espécie tentativa Bidens mosaic vírus - BiMV, descrita inicialmente em alface por Costa \& Kitajima (2). Ele é comumente encontrado infectando campos de girassol, causando redução no tamanho das plantas e das inflorescências, além de também ser verificado em ervilha e margarida- amarela (Coreopsis sp.), causando mosaico nas folhas e em alface (5).

O BiMV ainda é considerado uma espécie tentativa pelo International Comitee on Taxonomy of Viruses (ICTV) (1). Recentemente, com base em estudos filogenéticos realizados com um fragmento de 1700 pares de bases de isolados de BiMV provenientes de B. pilosa e P.sativum, correspondente a parte das regiões codificadoras para a NIb, CP e região não traduzida no terminal 3', foi proposto que o BiMV poderia ser uma estirpe do Potato virus $Y$ (PVY) (4).

No verão de 2004, em campos de alface localizados no município de São Manuel, SP foi verificada alta incidência de mosaico, parecido ao causado pelo LMV. Testes de RT-PCR com oligonucleotídeos específicos para o LMV (11) foram negativas para 
este vírus. Inoculações em plantas de girassol foram inicialmente realizadas para verificar a possível ocorrência de BiMV, porém estas não foram infectadas pelo potyvírus. Ao Microscópio Eletrônico de Transmissão Phillips CM100, partículas flexuosas medindo aproximadamente $730 \mathrm{~nm}$, típicas dos potyvírus, foram visualizadas.

Deste modo iniciou-se uma avaliação da gama de hospedeiro e análise molecular parcial para identificação da provável espécie viral. A purificação biológica, por meio de três passagens sucessivas de monolesionais obtidas em Chenopodium quinoa, foi realizada anteriormente à inoculação nas diferentes espécies de plantas. As inoculações foram realizadas via extrato vegetal preparado com tampão

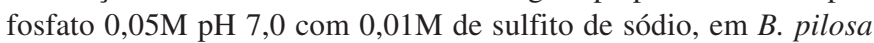
(picão-preto), C. quinoa, C. amaranthicolor, Datura stramonium, Gomphrena globosa, Helianthus annuus "Catissol", Nicotiana clevelandii, $N$. occidentalis, $N$. glutinosa, N. rustica, N. tabacum TNN, N. tabacum Havana 425, N. tabacum Turkish, N. tabacum Xanthi, N. benthamiana, Lycopersicon esculentum 'Santa Clara', Nicandra physaloides, Physales floridana, Sonchus oleraceus, Pisum sativum e as cultivares de L. sativa Trocadero, White Boston, Regina, Verônica, Lucy Brown, Rafaela, Tainá, Gizele, Vera e Laurel.

Para a minipurificação viral foi utilizado o método de Lane (7) e posterior extração de RNA com tratamento com proteinase K, extração com fenol/clorofórmio e precipitação com etanol. Foi realizada a reação de transcrição reversa com o oligonucleotídeo PV1 (5' GAT TTA GGT GAC ACT ATA GTT TTT TTT TTT TTT TTT 3') (9) utilizando-se a enzima AMV reverse transcriptase (Promega). A reação de PCR foi realizada utilizando-se cDNA e os oligonucleotídeos WCIEN (5' ATG GTT TGG TGY ATY GAR AAT 3') e PV1, ambos descritos por Mota et al., (9) e os oligonucleotídeos 8331 (5' CGT GGG GCT ATC CTG AAT TG 3') e 9046 (5' CCA CAT CAG AGA AGT GTG CC 3') desenhados a partir das sequências disponíveis no GenBank, cobrindo a região codificadora para proteína capsidial do BiMV. A reação foi realizada em um volume de $25 \mathrm{ml}$ contendo Tris- $\mathrm{HCl} 10 \mathrm{mM}$ pH 8,8, Triton $\mathrm{X}-100$ a $0,2 \%$ (v/v), $\mathrm{MgCl}_{2} 0,75 \mathrm{mM}, 0,25 \mathrm{mM}$ da mistura de nucleotídeos, $1 \mathrm{mM}$ de cada oligonucleotídeo e 2,5 unidades de Taq DNA Polimerase. O ciclo utilizado para os oligonucleotídeos WCIEN/PV 1 consistiu de 2 minutos à $95^{\circ} \mathrm{C}$ e 35 ciclos de $94^{\circ} \mathrm{C} / 60$

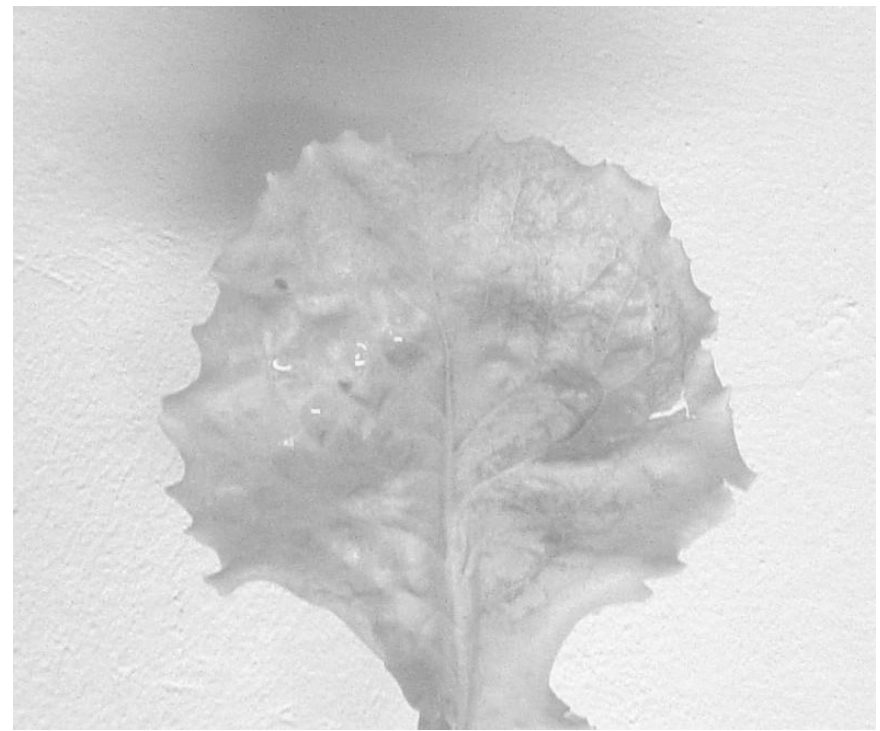

Figura 1. Sintomas de mosaico observados em alface White Boston.

segundos, $42^{\circ} \mathrm{C} / 2$ minutos e $72^{\circ} \mathrm{C} / 2$ minutos e finalizando com $72^{\circ} \mathrm{C} / 10$ minutos. Para os oligonucleotídeos $8333 / 9046$ consistiu de 2 minutos à $95^{\circ} \mathrm{C}$ e 39 ciclos de $92^{\circ} \mathrm{C} / 30$ segundos, $50^{\circ} \mathrm{C} / 1$ minuto e $72^{\circ} \mathrm{C} / 90$ segundos e finalizando com $72^{\circ} \mathrm{C} / 10$ minutos.

$\mathrm{O}$ produto de PCR foi purificado com o Kit SV Gel and PCR Clean UP system (Promega) e ligado no vetor pGEM-T Easy (Promega) de acordo com as instruções do fabricante. A transformação foi realizada com bactérias competentes Escherichia coli estirpe XL1. As sequências de nucleotídeos e de aminoácidos deduzidos foram analisadas utilizando-se o programa Blastn e CLUSTALW (12). Análises filogenéticas com outros isolados depositados no Gen Bank foram realizadas com o programa Mega 3.1 pelo método de neighbor-joining com valor de bootstrap 2000 repetições (6).

Verificou-se que, dentre as plantas hospedeiras testadas, o potyvirus em questão infectou C. quinoa e C. amaranthicolor causando inicialmente lesões locais cloróticas seguidas de mosaico sistêmico. Plantas de ervilha foram assintomáticas e em todas as

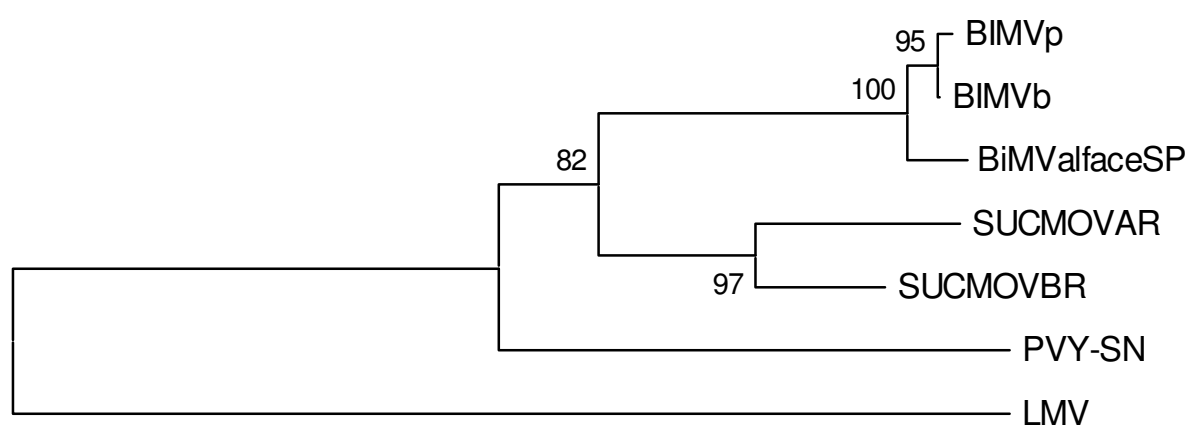

0.05

Figura 2: Árvore filogenética obtida pelo programa Mega 3.1, pelo método de Neighbor-joining com valor de bootstrap de 2000 repetições, para a região codificadora para a proteína capsidial dos isolados de Bidens mosaic virus isolado de alface (BiMValfaceSP caracterizado neste trabalho), de Bidens pilosa (BiMV-b número de acesso AY960151) e de Pisum sativum (BiMV-p número de acesso AY960150), Sunflower chlorotic mottle virus (SuCMoVAR número de acesso AF255677 e SucMoVBR número de acesso AY344048), Potato virus $Y$ (PVY-SN número de acesso AJ439544) e como outgroup Lettuce mosaic virus (LMV número de acesso AJ278854). 
cultivares de alface testadas o vírus causou mosaico (Figura 1), com exceção da Gizele, que permaneceu assintomática. Todas as demais espécies de plantas, incluindo B. pilosa (14 plantas inoculadas), não permitiram a multiplicação viral, comprovada por meio de retroinoculação em C. quinoa.

Com base nas análises realizadas com a seqüência correspondente a região codificadora para capa proteíca e da região terminal 3' não traduzida (UTR) do potyvírus em estudo, concluiuse que trata-se de um isolado da espécie tentativa BiMV, uma vez que maior identidade de aminoácidos (97\%) para a capa protéica e de nucleotídeos para a região UTR $(98 \%)$ foi obtida entre isolados deste vírus, além disso, verificou-se que o isolado de BiMV de alface compartilha o mesmo ancestral comum com o BiMV, sustentado por $100 \%$ de bootstrap (Figura 2). No entanto, o círculo de hospedeiras deste isolado de BiMV difere dos demais isolados deste vírus até então estudados, sendo incapaz de infectar B. pilosa, $H$. annus, $N$. tabacum TNN, P. hybrida e Z. elegans.

O Sunflower chlorotic mottle virus (SuCMoV), isolado de Zinnia elegans (8) apresenta relacionamento sorológico com BiMV e infecta girassol, mas não infecta alface. Alguns isolados de SuCMoV são capazes de infectar B. pilosa e outros não $(3,8)$. Estes resultados indicaram que o $\mathrm{SuCMoV}$ poderia ser uma estirpe de BiMV. Ambos, SuCMoV e BiMV foram estudados por InoueNagata et al. (4) e apresentaram uma identidade acima de $80 \% \mathrm{com}$ o Potato virus $Y$ (PVY) quando comparada seqüência de aminoácidos da região codificadora para capa protéica. No entanto, apenas o BiMV foi considerado uma provável estirpe de PVY, dada semelhança na gama de hospedeiros entre estes vírus. Este trabalho demonstra que existe maior variabilidade biológica entre isolados de BiMV do que se imaginava, e que é muito precoce caracterizar o BiMV como uma estirpe de PVY.

O BiMV proveniente de alface foi capaz de causar sintomas em grande parte das cultivares de alface testadas, com exceção da 'Gizele', que se mostrou tolerante ao vírus, podendo ser indicada em áreas onde esteja ocorrendo este vírus no campo.

O BiMV já havia sido descrito em alface (2), porém se desconhecem relatos da importância econômica deste vírus nesta cultura. Este trabalho foi iniciado justamente pela alta ocorrência de um potyvirus causando sintomas de mosaico e deformação foliar semelhantes ao causado pelo LMV, porém não relacionado a ele, em campos de produção experimental de alface em São Manuel, SP. Isto é um indicativo de que o BiMV pode estar sendo confundido visualmente com o LMV no campo, causando prejuízos à cultura.

\section{AGRADECIMENTOS}

Os autores agradecem ao auxílio financeiro da FAPESP Processo ${ }^{\circ}$ 2007/04162-4 (Fundação de Amparo à Pesquisa do Estado de São Paulo).

\section{REFERÊNCIAS BIBLIOGRÁFICAS}

1. Berger, P.H.; Adams, M.J.; Barnett, O.W.; Brunt, A.A.; Hammond, J.; Hill, J.H.; Jordan, R.L.; Kashiwazaki, S.; Rybicki, E.; Spence, N.; Stenger, D.C.; Ohki, S.T.; Uyeda,VI.; Van Zaayen, A.; Valkonem,J.; Vetten, H.J.. Potyviridae. In: Fauquet, C.M.; Mayo, M.A.; Maniloff,J.; Desselberger, U.; Ball,L.A. Virus taxonomy : Eighth Report of the International Committee on Taxonomy of Viruses. San Diego: Academic Press, 2005.p.819-842.

2. Costa, A.S.; Kitajima, E.W. Virus do mosaico do picão ataca girassol. O Estado de São Paulo, 30 nov. 1966. Suplemento Agrícola, p. 13.

3.Dujovny, G.; Usugi, T.; Shohara, K.; Lenardon, S.L. Characterization of a Potyvirus infecting sunflower in Argentina. Plant Disease, St. Paul, v.82, p.470-474, 1998.

4.Inoue-Nagata, A.K.; Oliveira, P.A.; Dutra, L.S.; Nagata, T. Bidens mosaic virus is a member of the Potato virus $Y$ species. Virus Genes, New York, v.33, p.45-49, 2006.

5.Kitajima, E. W.; Carvalho, A. M. B.; Costa, A. S. Morfologia do vírus do mosaico do picão. Bragantia, Campinas, v. 20, n. 13, p. 503-512, 1961.

6.Kumar, S.; Tamura, K; Nei, M. MEGA3: Integrated software for Molecular Evolutionary Genetics Analysis and sequence alignment. Briefings in Bioinformatics, Oxford, v. 5, p. 150-163, 2004.

7.Lane, L. A general method for detecting plant viruses. In: Maramorosch, K. (Ed.) Plant diseases of viral, viroid, mycoplasma and uncertain origin. New Delhi: Oxford \& IBH Publishing, 1992. p.1-15.

8. Maritan, A.C.; Gaspar, J.O.; Camargo, L.E.A. Identificação e caracterização de um potyvírus isolado de Zinnia elegans. Fitopatologia Brasileira, Brasília, v.29, p.28-33, 2004.

9.Mota, L.D.C.; Della Vecchia, M.G.S.; Gioria, R.; Kitajima, E.W.; Rezende, J.AM.; Camargo, L.E.A.; Amorim, L. Pfaffia mosaic virus: a new potyvirus found infecting Pfaffia glomerata in Brazil. Plant Pathology, London, v. 53, p. 368-373, 2004.

10. Pavan, M.A.; Krause-Sakate, R.; Silva, N. da; Zerbini, F.M.; Le Gall, O. Virus diseases of lettuce in Brazil. Plant Viruses - Global Science Books, London, v.2, p. 35-41, 2008.

11. Revers F.; Lot, H.; Souche, S.; Le Gall O; Candresse, T.; Dunez, J. Biological and molecular variability of lettuce mosaic virus isolates. Phytopathology, St. Paul, v. 87, p.397-403, 1997.

12.Thompson, J.D.; Higgins, D.G.; Gibson, T.J. CLUSTAL W: Improving the sensitivity of progressive multiple sequence alignment through sequence weighting,position-specific gap penalties and weight matrix choice. Nucleic Acids Research, Oxford, v.22, p. 4673-4680, 1994. 